\title{
Removal of Azo Dye from Aqueous Solutions using Chitosan
}

\author{
A. ZUHAIR JABBAR ${ }^{1}$, ANGHAM G. HADI ${ }^{2 *}$ and FERDOOS SAMI ${ }^{3}$ \\ ${ }^{1}$ College of Engine Materials, Babylon University, Iraq. \\ ${ }^{2-3}$ Chemistry Department, College of Science, Babylon University, Iraq. \\ ${ }^{*}$ Corresponding author E-mail: analhusainy @gmail.com
}

http://dx.doi.org/10.13005/ojc/300222

(Received: January 11, 2014; Accepted: March 03, 2014)

\begin{abstract}
Adsorption of Congo Red (CR) from aqueous solution onto chitosan was investigated in a batch system. The effects of solution $\mathrm{pH}$, initial dye concentration, and temperature were studied. Results indicated that chitosan could be used as a biosorbent to remove the azo dyes from contaminated water. Synthesize of chitosan involved three main stages as preconditioning, demineralization, deproteinization and deacetylation. Chitosan was characterized using Fourier Transform Infrared Spectroscopy (FTIR) and solubility in 1\% acetic acid.
\end{abstract}

Key words: Adsorption; Congo red; Chitosan, synthesized.

\section{INTRODUCTION}

The chemical contamination of water from a wide range of toxic derivatives is an important environmental problem ${ }^{1}$. Synthetic dyes usually have a complex aromatic molecular structure, which possibly comes from coal-tar based hydrocarbons such as benzene, naphthalene, toluene, xylene, etc. The complex aromatic molecular structures of dyes make them more stable and more difficult to biodegrade ${ }^{2-4}$. It is known that wastewaters containing dyes are very difficult to treat, since the dyes are recalcitrant molecules (particularly azo dyes), resistant to aerobic digestion, and are stable to oxidizing agents. Textile, paper, plastics, and cosmetic industries use a wide variety of dyes to color their products and discharge large amount of effluents including dyes which are very toxic and could cause serious ecological problems. Therefore, dye pollution in water stream is a major environmental problem ${ }^{5}$.

The methods of dye removal from industrial wastewaters could require many processes such as biological treatment, coagulation, electrochemical techniques, adsorption, and oxidation. Among these methods, adsorption is considered an effective and economical method to remove dyes from wastewaters $^{6-11}$. It has been reported that many different types of adsorbents are effective in removing color from aqueous effluents. Natural 
polymeric materials are gaining more and more interest for application as adsorbents in wastewater treatment due to their biodegradable and non-toxic nature. Currently, the most common procedure involves the use of activated carbon ${ }^{12}$. Activated carbon is regarded as an effective but expensive adsorbent due to the high cost of manufacturing and regeneration. Because of its relatively high cost, there have been attempts to utilize low cost and naturally occurring adsorbents. There are many different studies on the use of low cost materials such as various agricultural wastes ${ }^{13-15}$, Chitosan (CS) offers an interesting set of characteristics, including non-toxicity, biodegradability, biocompatibility, and bioactivity.

Chitosan and its derivatives have been extensively investigated as biosorbents ( figure 1) for removal of heavy metals and dyes ${ }^{16-20}$.

The overall objective of this study is to investigate the dye removal from wastewater by adsorption using chitosan. The specific objectives included; synthesize chitosan from fish shells and removal of Congo red dye using as a bio-adsorption material.

\section{MATERIALS AND METHODS}

\section{Preparation of Sorbent}

Traditional isolation of chitin consists of four traditional steps (Figure 2): demineralization (DM), deproteinization (DP), decolorization (DC), and deacetylation (DA).

\section{Preparation of Adsorbent}

Congo red contains an azo $(-\mathrm{N}=\mathrm{N}-)$ chromophore and an acidic auxochrome (sulfonate : -SO3H) (which, respectively, gives and reinforces the coloration) associated with the benzene structure. Congo red is a the sodium salt of a derivative of benzidine and naphthionic acid as in figure 3 .

\section{Batch adsorption experiments}

A stock solution of $C R(1.0 \mathrm{~g} / \mathrm{L})$ was prepared by dissolving $1 \mathrm{~g}$ of $\mathrm{CR}$ powder in $1 \mathrm{~L}$ of double distilled water. The desired concentrations ranging from 10 to $60 \mathrm{mg} / \mathrm{L}$ were obtained by dilution. For each adsorption experiment, $50 \mathrm{ml}$ of the dye solution with a specified concentration was stirred at $100 \mathrm{rpm}$ in a glass flask. The $\mathrm{pH}$ of solutions was adjusted to a desired value by adding $0.1 \mathrm{~mol} / \mathrm{L} \mathrm{NaOH}$ or $\mathrm{HCl}$ solution. Batch adsorption experiments were carried out using a thermostated shaker for a certain contact time at a determined temperature at $100 \mathrm{rpm}$. At predetermined time intervals, samples were withdrawn by a pipette and centrifuged at $4000 \mathrm{rpm}$. Then, the residual concentration was determined from a constructed calibration curve by measuring the absorbance at $\lambda_{\max }=498 \mathrm{~nm}$ using UV-Vis spectrophotometer.

Batch adsorption experiments were carried out to examine effects of adsorbent dosage, initial dye concentration, solution $\mathrm{pH}$, and time on the adsorption of $\mathrm{CR}$ on chitosan.

The amount of $\mathrm{CR}$ adsorbed on chitosan (at a predetermined time $t$ ), qt (in $\mathrm{mg} / \mathrm{g}$ ), was determined using the mass balance equation:

$$
q t=(C-C t) \times m / v
$$

The decolorization rate (.) of CR was calculated by the following equation:

$$
\mu=C o ́-C t) / \text { Cóx } 100 \%
$$

where $C_{0}$ is the initial concentration of $\mathrm{CR}$ (in $\mathrm{mg} / \mathrm{L}$ ), $C t$ (in $\mathrm{mg} / \mathrm{L}$ ) is the instant concentration of $\mathrm{CR}$ at a predetermined time $t, V$ is the volume of the solution (in L), and $m$ is the mass chitosan (in $\mathrm{g}$ ).

\section{RESULTS AND DISCUSSION}

\section{Effect of adsorbent dosage}

The effect of adsorbent dosage (varied from 0.025 to $0.25 \mathrm{gm}$ ) on the percentage removal of $50 \mathrm{mg} / \mathrm{L} \mathrm{CR}$ solution is shown in Fig. 3. The percentage removal of $\mathrm{CR}$ from the solution increased from $30 \%$ to $86 \%$ as the adsorbent dosage increased from 0.025 to $0.25 \mathrm{gm}$. This result is expected because of the increased adsorbent surface area and availability of more adsorption sites caused by increasing adsorbent dosage ${ }^{23,24}$.

\section{Effect of solution $\mathrm{pH}$}

The $\mathrm{pH}$ of the dye solution affects the surface charge of the adsorbent, the degree of 


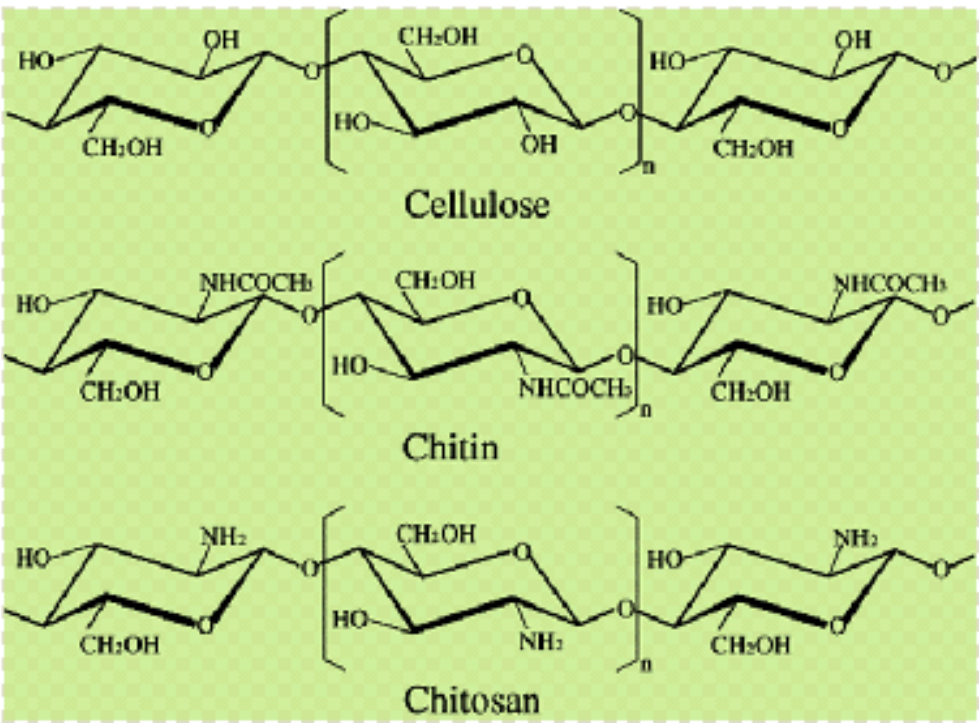

Fig. 1: Chemical structures of chitin, chitosan and cellulose ${ }^{21}$

Wet crawfis h shell

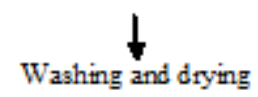

Grinding and sieving

Deprotelnization

$3 \% \mathrm{NaOH}(\mathrm{w} / \mathrm{v})$

for $1 \mathrm{~h}$ at $\mathrm{b} . \mathrm{p}^{\circ} \mathrm{C}$, solid:

solvent $(1: 10, \mathrm{w} / \mathrm{v})$

Washing

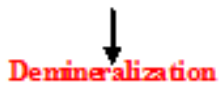

$1 \mathrm{~N} \mathrm{HCl}$ for $30 \mathrm{~min}$ at

room temp., solid :

solvent $(1: 15, \mathrm{w} / \mathrm{v})$

Washing and Drying

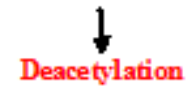

$50 \% \mathrm{NaOH}$ for $2 \mathrm{hr}$. at $/ 90^{\circ} \mathrm{C}$

solid solvent $(1: 10, \mathrm{w} / \mathrm{v})$

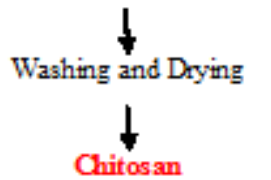

Fig. 2: Traditional Chitosan Production ${ }^{22}$ ionization of the materials, and the dissociation of functional groups on the active sites of the adsorbent. As well, it affects the structure of the dye molecule ${ }^{25}$. The percentage removal of $\mathrm{CR}$ at different $\mathrm{pH}$ values is plotted in Fig. 4. The percentage removal increased from $24.29 \%$ to $80.85 \%$ when $\mathrm{pH}$ was decreased from 10 to 2 . This was because the CR molecule (with one sulfuric group) ionized easily even in acidic media and became a soluble CR anion. As the initial solution $\mathrm{pH}$ decreased, the number of positively charged active sites increased due to the protonation of the amine groups $\left(-\mathrm{NH}_{2}\right)$ in the CS chain. Consequently, the electrostatic interaction between the positively charged adsorbent and the CR anions increased, which resulted in increased adsorption. Furthermore, the lower adsorption removal percentage at alkaline $\mathrm{pH}$ contributed to the presence of excess hydroxyl ions, which competed with the CR molecules for adsorption sites $^{23}$. In contrast, as expressed in equilibrium equation (3), the quinoid structure of $\mathrm{CR}$ is more easily reduced than its azo structure ${ }^{26}$. Therefore, higher removal percentages were observed at acidic $\mathrm{pH}$ values for $\mathrm{CR}$ adsorption.

\section{Effect of contact time}

A $50 \mathrm{ml}$ of $50 \mathrm{mg} / \mathrm{L}$ of CR dye was taken in conical flasks and treated with $0.1 \mathrm{gm}$ chitosan (adsorbent) at several times $(20,40,60,80,100$, 120 and $140 \mathrm{~min}$.). the variation in percent removal of dye with the time was shown in figure 5 . The 
percentage removal increased from $31.41 \%$ to $80.60 \%$ when time was increased from 20 to 140 min., this due to saturation of active sites which do not allow further adsorption to take place ${ }^{27}$.

\section{Effect of initial CR concentration}

The effect of initial CR concentration on the percentage removal of the dye is shown in figure 6. The initial $\mathrm{CR}$ concentration was varied from 10 to $60 \mathrm{mg} / \mathrm{L}$. A rapid initial adsorption of CR took place within the first $20 \mathrm{~min}$, after which the adsorption slowed down and then almost reached equilibrium at $120 \mathrm{~min}$. The percentage of CR removal evidently decreased with increasing initial dye concentration. The percentage removal was $82.05 \%$ for $10 \mathrm{mg} / \mathrm{L}$ initial concentration, and only $30.26 \%$ for $60 \mathrm{mg} / \mathrm{L}$ after 120 min of adsorption (figure 6). This was caused by an increase in the mass gradient

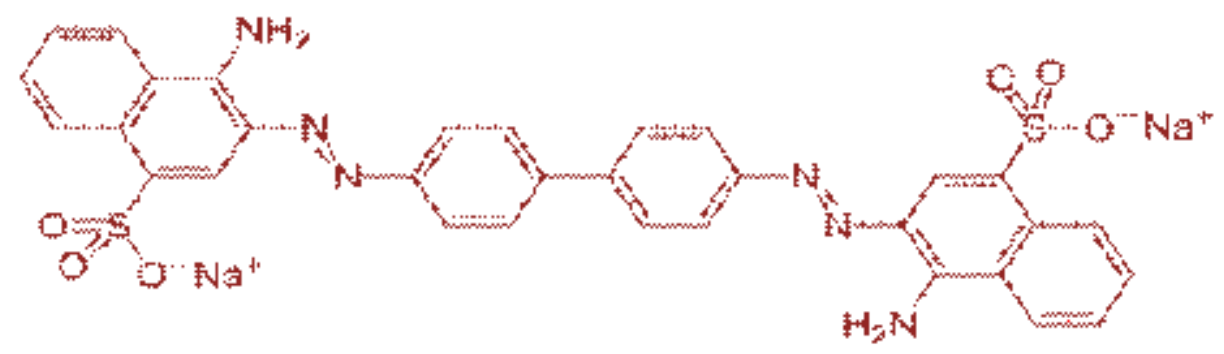

Fig. 3: Chemical structure of Congo red dye

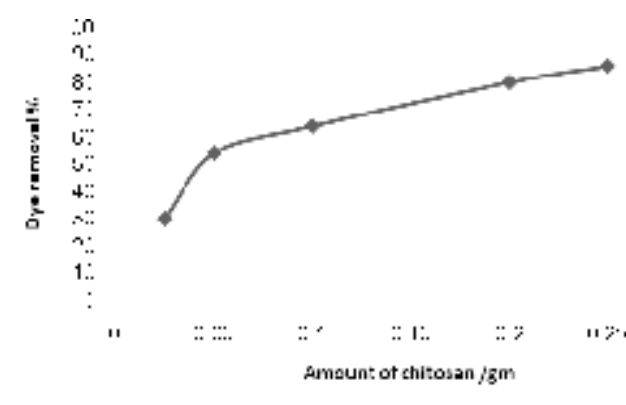

Fig. 3: Effect of adsorbent dosage in CR removal

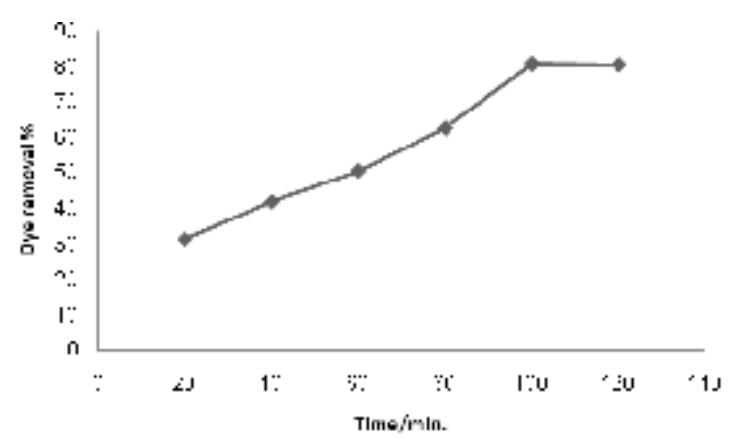

Fig. 5: Effect of contact time on CR adsorption $(50 \mathrm{mg} / \mathrm{L})$ by $0.1 \mathrm{gm}$ chitosan

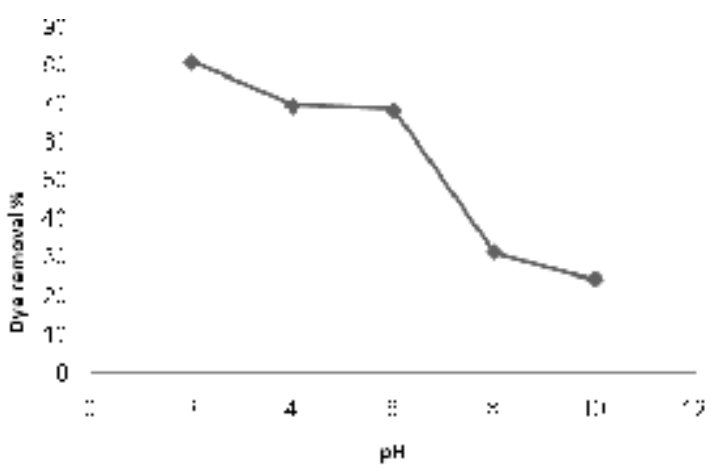

Fig. 4: Adsorption of CR by chitosan as a function of $\mathrm{pH}$ at initial concentration of $50 \mathrm{mg} / \mathrm{L}$ and adsorbent dosage $0.1 \mathrm{~g}$

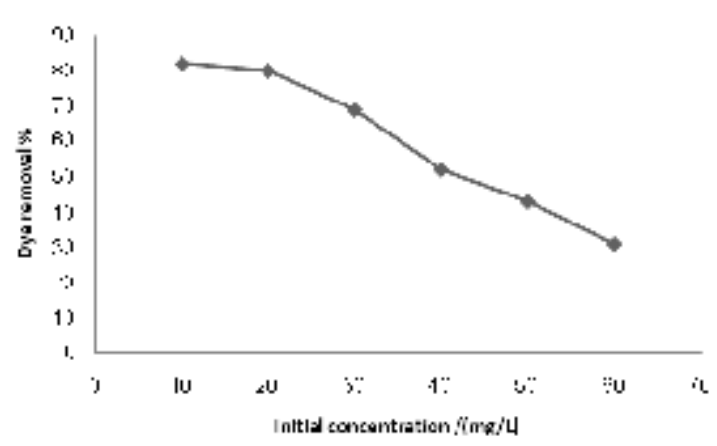

Fig. 6: Effect of different initial CR concentration on dye removal 
pressure between the solution and adsorbent. The gradient acted as the force that drove the transfer

Tabel 1: The physiochemical properties of this dye can be shown

\begin{tabular}{lc}
\hline Parameter & Value \\
\hline Molecular formula & $\mathrm{C}_{32} \mathrm{H}_{22} \mathrm{~N}_{6} \mathrm{Na}_{2} \mathrm{O}_{6} \mathrm{~S}_{2}$ \\
Molecular weight & 696.665 \\
Maximum adsorption & $498 \mathrm{~nm}$ \\
Nature & Anionic dye \\
\hline
\end{tabular}

of the dye molecules from the bulk solution to the particle surface ${ }^{23}$.

\section{CONCLUSIONS}

The synthesize of chitosan involved three main stages demineralization, deproteinization, and deacetylation., it characterized by using Fourier Transform Infrared Spectroscopy (FTIR) and solubility in $1 \%$ acetic acid. CR adsorption onto the chitosan depended highly on adsorbent dosage, initial dye concentration, solution $\mathrm{pH}$ and time.

\section{REFERENCES}

1. Singh, V., Sharma, A. K., Tripathi, D. N., Sanghi,R.,J. Hazard. Mater. 2009, 161, 955966.

2. Fewson,C. A., Trends Biotechnol. 1988, 6,148-153.

3. Seshadri,S.,Bishop, P. L., AghaA. M., Waste Manage. 1994, 15, 127-137.

4. Nigam, P.,Armour, G.,Banat, I. M.,Singh D.,Marchant,R., Bioresour. Technol. 2000, 72, 219-226.

5. Perju,M. M. and Dragan,E. S.,iel, 2010, 3, 711.

6. Chiou M. S., Li H. Y., Chemosphere 2003 , 50,1095-1105.

7. Rauf M. A., Bukallah S. B., Hamour F. A., Nasir A. S., Chem. Eng. J. 2008,137, 238- 243.

8. Mittal A., Mittal J., Malviya A., Kaur D., Gupta V. K., J. Colloid Interface Sci. 2010, 343, 463473.

9. Chakraborty S., De S., DasGupta S., Basu J. K., Chemosphere 2005,58 , 1079-1086.

10. Dragan S., Cristea M., Arinei A., Poinesculg., Luca C., J. Appl. Polym. Sci. 1995, 55 421430.

11. Wawrzkiewicz M., H, Hubicki Z., Chem. Eng. J. 2010, 157 29-34.

12. Calvete,T.,Lima, E. C.,Cardoso, N. F.,Dias, S. L. P.,Ribeiro, E. S.,Clean - Soil Air Water 2010, 38 5-6), 521-532.

13. SahaP.,Chowdhury S., Gupta, S., Kumar, I., R. Kumar, Clean - Soil Air Water 2010, 38 (56), 437-445.

14. Aksu,Z., Tezer,S., Process Biochem. 2000,
36 (5), 431-439.

15. Aksu, Z., Biochem. Eng. J. 2001, 7 (1), 7984.

16. Crini G., Badot P.-M., Prog.Polym.Sci. 2008, 33 , 399-447.

17. Dragan E. S., Dinu M. V., Timpu D., Bioresour. Technol . 2010, 101, 812-817.

18. Chatterjee S., Chatterjee S., Chatterjee B. P., Guha A. K., Colloids Surf. A 2007 ,299, 146-152.

19. Hadi,A. G., British journal of science,2012, 5 (2).

20. Hadi,A. G.,BJS,2012, 6(2).

21. WEB_4.Dalwoo-ChitosanCorporation, http; // members.tripod.com/Dalwoo/structure 2007.

22. Meyers, S.P. and No, H.K.,Lim, C.E and Sessa, D.J. (Eds.),1995, . 269-277. AOCS Press, Champaign, IL.

23. Wang,L., J. Zhang, R. Zhao, C. Li, Y. Li, C.L. Zhang,Desalination, 2010, 254 (1-3),. 6874.

24. P.S. Kumar, S. Ramalingam, C. Senthamarai, M. Niranjanaa, P. Vijayalakshmi, S. Sivanesan, Desalination, 2010,261 (1-2). . 52-60.

25. G. Crini, H.N. Peindy, F. Gimbert, C. Robert, Sep. Purif. Technol., 2007,53 (1),. 97-110.

26. V.F. Chemie, PhD thesis. Duisburg University, Germany, 2005.

27. W. Nakbanpote,P. Thiravavetyan and C. Kalambaheti,Mineral Eng., 2002,13,391552. 